\title{
An Open and Shut Case: The Interaction of Magnesium with MST Enzymes
}

Kathleen M. Meneely, Jesse A. Sundlov, Andrew M. Gulick, Graham R. Moran and Audrey L.

Lamb

Supplemental Figure: Below are the binding isotherms that were used to determine the dissociation constants that are shown in the tables of Figure 6 and Figure 9. The color coding is the same as in the manuscript proper: $\mathrm{PchA}=$ red; EntC = green; Irp9 = blue. Error bars are not visible, because they are smaller than the markers.

E•chorismate (Irp9 binding isotherm is Figure 6B)
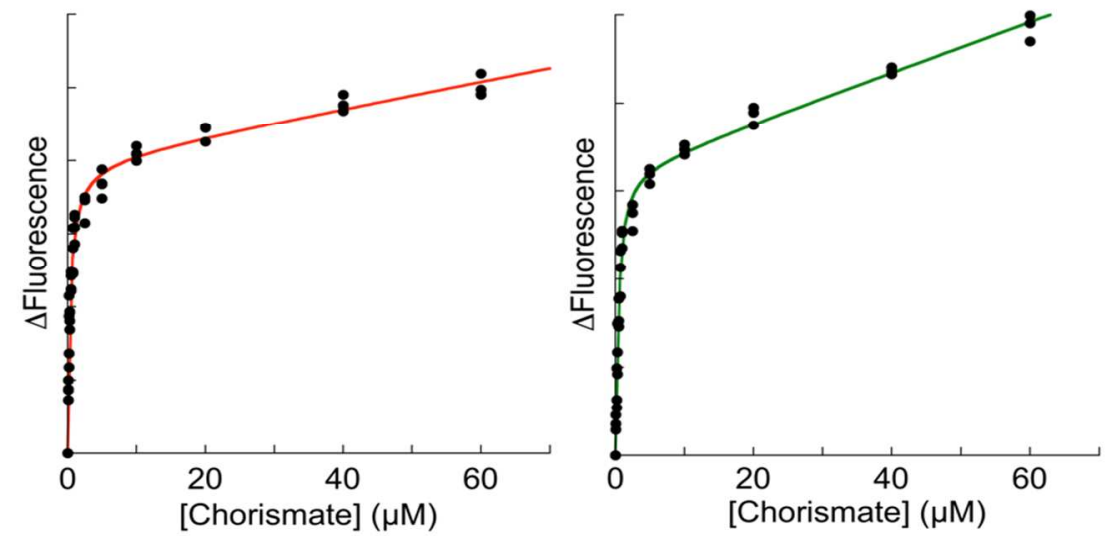

E•isochorismate
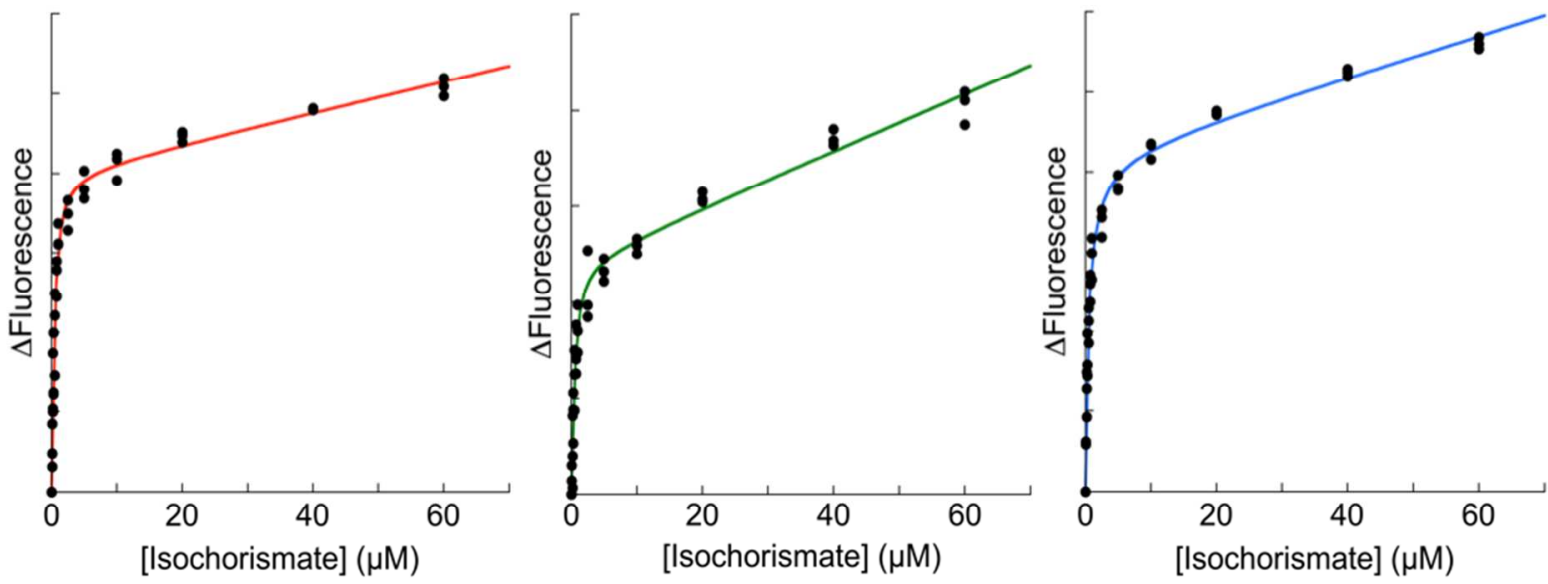


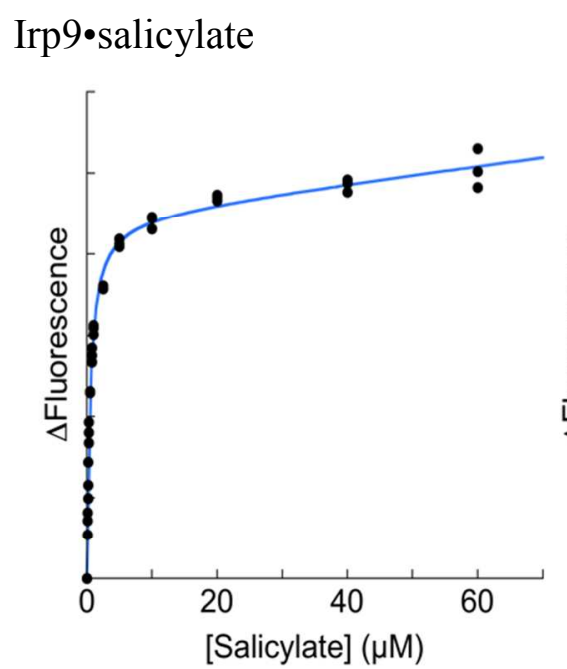

Irp9•pyruvate

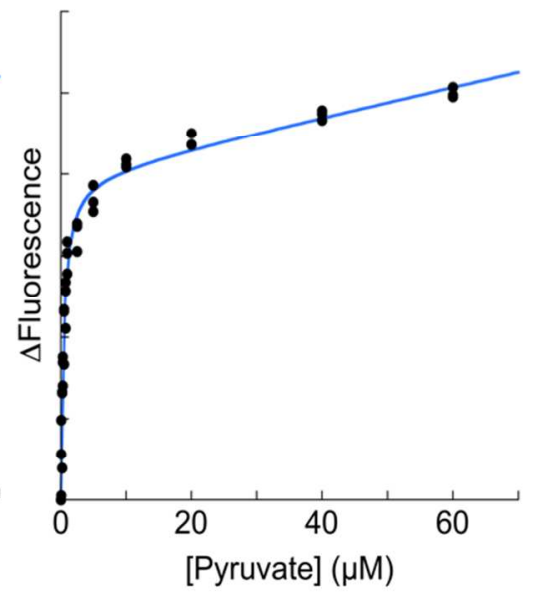

$\mathrm{E} \bullet \mathrm{Mg}(\mathrm{II})$ (Irp9 binding isotherm is Figure 6C)

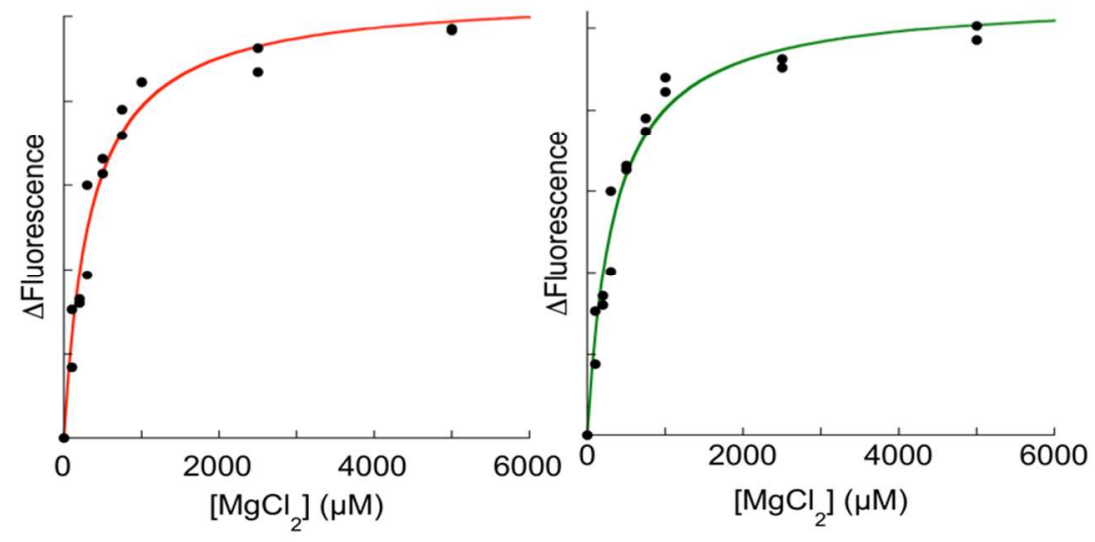

\section{$\mathrm{E} \cdot \mathrm{Fe}(\mathrm{II})$}
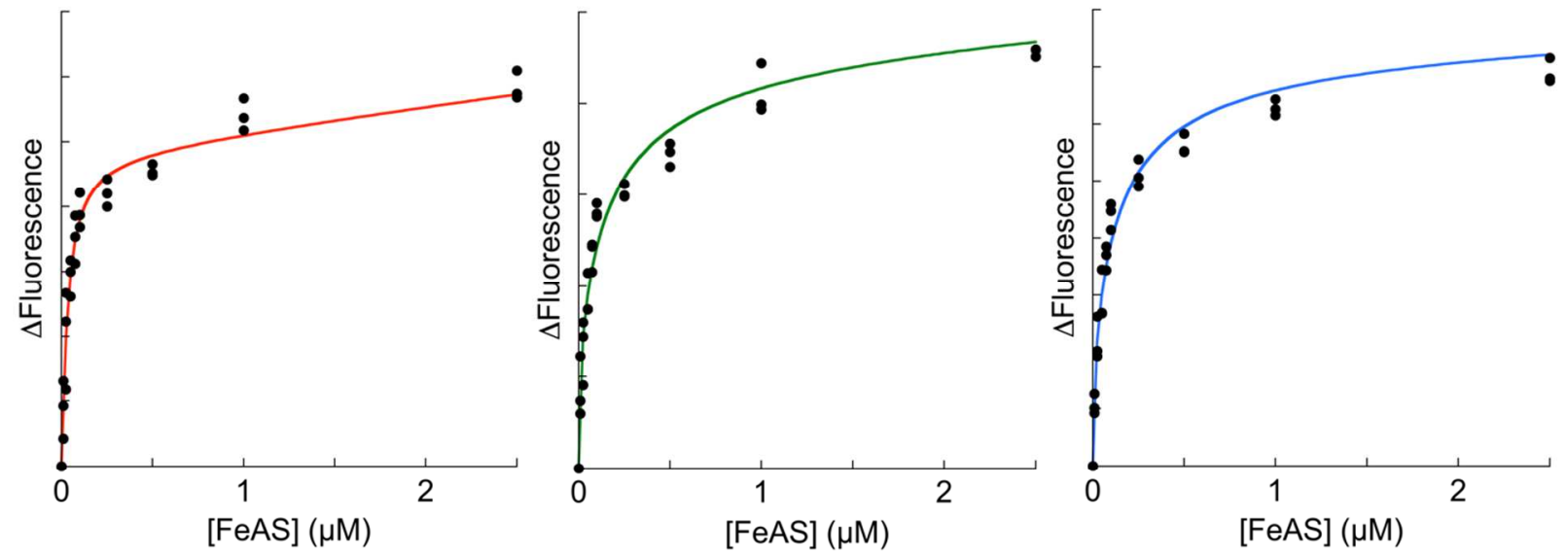